\title{
EVALUATION OF GOLD NANOPARTICLES COATED SANDWICH ELISA AS INNOVATIVE DIAGNOSIS FOR HUMAN BANCROFTIAN FILARIASIS
}

\section{By}

OMAIMA K. EL-SHAFEY ${ }^{1}$, AMIRA F. AFIFI ${ }^{1}$, SALWA F. OSHIBA ${ }^{1}$, IBRAHIM R. AL ${ }^{2}$ and MARWA E. LASHEEN ${ }^{1^{*}}$

Department of Parasitology ${ }^{1}$, Faculty of Medicine, Menoufia University, Department of Immunology and Parasitology ${ }^{2}$, Theodor Bilharz Institute, Imbaba P.O. Box 30, Giza, Egypt ( ${ }^{*}$ Correspondence: Email marwalasheen70@yahoo.com)

\section{Abstract}

This study compared the traditional sandwich ELISA and nano-sandwich ELISA methods for diagnosis of lymphatic filariasis. With the ability to interact with matter at the nanoscale, the development of nanotechnology architecture and materials could potentially extend molecular detection beyond the limits of conventional diagnostic modalities. This study included 142 subjects who were classified into; filarial diseased, other parasitic diseased and healthy control groups. Firstly, thick blood film was done for all subjects under study and their sera were obtained and preserved. A prepared sitarial antigen was injected into a rabbit to obtain polyclonal antibodies. That rabbit serum was purified, then pure IgG was obtained and a part of it was conjugated with gold nanoparticles. Conventional ELISA and nano-ELISA were done for patient's serum to detect circulating filarial antigen. Examination of blood film for microfilaria resulted in that; $5.1 \%$ of all patients were positive however $94.9 \%$ were negative. In comparison between ELISA and nano-ELISA readings, it was obvious that nano-ELISA is advantageous than traditional ELISA in all cases. The sensitivity, specificity, positive predictive value and negative predictive value of ELISA were $90.7 \%, 75 \%, 84.8 \%$ and $84 \%$ respectively. While by using nano-ELISA, they were $95.1 \%, 87.5 \%, 92.9 \%$ and $91.3 \%$ respectively. It was concluded that using nano-sandwich ELISA of the serum samples for detection of circulating filarial antigen in patients infected with $W$. bancrofti gave higher sensitivity and specificity than conventional ELISA, as proved by statistical study.

Key words: Filariasis, Blood, ELISA, Gold, Nanoparticles.

\section{Introduction}

Filariasis is a disease caused by filarial worms, which are microscopic roundworms that live in lymphatic tissues of humans. The most critical form for humans is elephantiasis as it is a serious complication of this disease (Kabatereine et al, 2010). Lymphatic filariasis (LF) is caused by three species; Wuchereria bancrofti, Brugia malayi and Brugia timori. It was considered as one of the neglected tropical health problems of the $21^{\text {st }}$ Century (Simonsen and Mwakitalu, 2013). In Egypt, filariasis has been reported long ago (Halawani, 1951) and its insectvector (El-Bashier et al, 2006). Diagnosis of this disease can be based on the history of being in an endemic area and clinical examination of the affected limb. The most common presentation is unilateral or bilateral asymmetrical swelling of the limbs, which is of long duration and associated with thickening of the skin and history of repeated acute attacks of lymphangitis (Shenoy, 2008). Definitive diagnosis can be made by detection of microfilariae in blood film, circulating filarial antigen in patient's serum, filarial DNA using PCR in the blood or adult worms in lymphatics. In rare cases, microfilariae or adult worms can be found in tissue biopsies (Kumar et al, 2011).

Nanoscience is the study and manipulation of materials at the nanoscale, where properties differ significantly from those at a larger scale. In nanotechnology, a particle is defined as a small object that behaves as a whole unit and effective nanoparticles are sized between 1 \& 100 nanometers (Buzea et al, 2007). Nanomedicine is the nanotechnology used in diagnosis of diseases, drug design, drug delivery, treatment, monitoring 
and control of biological systems (Shelton et $a l, 2007)$. In disease diagnosis, it increases sensitivity, specificity and early detection as nanoparticles have a large surface area that enables attachment of large number of target specific molecules of interest for accurate detection (Padmavathy et al, 2010). Many forms of nanomaterials are found; liposomes, polymeric nanoparticles, dendrimers, solid lipid nanoparticles, carbon nanotubes and metallic nanoparticles (gold and silver) (Buzea et al, 2007). Gold nanoparticles (GNPs) were used in immunochemical studies for identification of the protein molecules (Tomar and Garg, 2013), as they exhibited unique physicochemical properties allowing surface modification and use in different biomedical applications (Shukla et al, 2005).

This study aimed to compare between conventional sandwich ELISA and Nano sandwich ELISA using gold nanoparticles in diagnosis of lymphatic filariasis.

\section{Subjects and Methods}

This cross-sectional study was carried out from January 2016 to October 2016 on patients from endemic areas of filariasis in Menoufia Governorate. Written informed consents were obtained from all patients. The work was performed in Theodor Bilharz Research Institute (TBRI), Giza, Egypt.

Study population: The study included 142 subjects who were classified according to clinical disease into 3 groups; GI $(n=78$, suspected filarial patients; based on their history, clinical picture and data obtained from Ministry of Health "filarial center"), GII ( $\mathrm{n}=54$, other parasitic patients infected with other parasites e.g. S. mansoni, F. gigantica and hookworms) and GIII $(\mathrm{n}=10$, healthy control persons). They represented both sexes; 62 males and 80 females of different age groups. They were selected from endemic areas for filariasis which were; Delehmo village (Ashmoun Center), Sirs ElLiayyan and villages around Qweisna and Berkat Al-Saba Centers (Menoufia Governorate).
All were subjected to the following after their consent; history taking, clinical and laboratory investigations, which included: examination of blood samples for microfilaria using thick blood film and serological tests for detection of the circulating filarial antigen (CFA) using sandwich ELISA and nano-sandwich ELISA methods.

Parasitological examination (Thick blood film): Fresh blood samples by finger-prick were collected at daytime from all subjects under study an hour after taking a single dose of $100 \mathrm{mg}$ diethylcarbimazine citrate (DEC) (Hetrazan, Wyeth Limited co.) for adults and $50 \mathrm{mg}$ for children (one tablet) as a provocative sample test (Garcia and Bruckner, 2001). Blood samples were examined microscopically for detection of microfilariae in thick blood films stained with Ge-imsa stain (Eberhard and Lammie, 1991).

Serological tests (ELISA \& Nano-ELISA): Venous blood samples about $4 \mathrm{ml}$ were taken from all individuals in EDTA tubes. Serum was separated by centrifugation at $2000 \mathrm{~g}$ for 10 minutes, fractionated into small Eppendorf tubes and stored at $-20^{\circ} \mathrm{C}$ until used (Gounoue-Kamkumo et al, 2015).

Animals: White New-Zealand male rabbit, weighing approximately $1.5 \mathrm{Kg}$ and about 2 months age, purchased from rabbit research unit (RRU), Faculty of Agriculture, Cairo University, Egypt. It was examined before the start of the experiments and used in the production of the antibodies (Abdel-Megeed and Abdel-Rahman, 2004). It was housed in the animal house in Theodor Bilharz Research Institute (TBRI), Giza, Egypt.

Parasite: Sitaria digitata (S. digitata) wor$\mathrm{ms}$ were recovered from diseased animals (donkeys) in the Faculty of Veterinary Medicine, Cairo University, Egypt. They were transferred to the laboratory in Theodor Bilharz Research Institute (TBRI) in Hanks' Balanced Salt Solution (HBSS) to stimulate normal ion concentration under physiological conditions (Waizy et al, 2012).

Preparation of antigen: The adult female worms of $S$. digitata were washed extensive- 
ly in phosphate buffer saline (PBS), and ultrasonicated for 1 minute. Then, they were collected and dialyzed overnight in $50 \mathrm{~mm}$ acetate buffer $(\mathrm{pH} 4.5)$ and treated with $25 \mathrm{~mm}$ sodium meta-periodate (Sigma) for 1 $\mathrm{h}$. The reaction was stopped by treating with $50 \mathrm{~mm}$ sodium borohydride for $30 \mathrm{~min}$ at room temperature and the sodium metaperiodate oxidized antigen was dialyzed extensively against PBS (Mohanty et al, 2001). Protein content was estimated by a Bio-Rad protein assay (Bradford 1976).

Purification of antigen by Diethyl [2-hydroxypropyl] aminoethyl (DEAE)-Sephadex A-50 (Smith et al, 1993): It is an effective method for separating proteins based on their charge. Sephadex A-50 powder was swelled in $0.5 \mathrm{M}$ Tris buffer. Then, it was poured in $30 \times 2.5 \mathrm{~cm}$ column and covered with the binding buffer, then the sample was dialyzed versus the binding buffer and its protein content was calculated. The buffer above the beads was removed. The protein content $<10 \%$ of column bed capacity was applied to the column using Pasteur pipette. The outlet tubing was opened till the sample penetration to the beads then closed again for 10 minutes for antigen binding to the beads. The outlet tubing was then opened and the beads were washed by 5 bead volumes binding buffer. The protein was eluted by $20 \mathrm{mM}$ Tris $150 \mathrm{mM} \mathrm{NaCl}$ under gravity by collecting $2 \mathrm{ml}$ of each fraction. Absorbance at $280 \mathrm{~nm}$ of each fraction was measured using spectrophotometer (Perkin-Elmer Lambda 1A). Fractions exhibited high absorbance at first peak was pooled together. The protein content was estimated by a BioRad protein assay (Bradford, 1976).

Purification of antigen by gel filtration chromatography on Sephacryl-S-200 high resolution (HR) column (Sun et al, 2004): It is a technique for separating proteins on the basis of molecular size. The fractions collected from sephadex A-50 ion exchange chromatography were further purified by DEAE sephacryl S-200 gel filtration column chromatography. The outlet of the column was opened for buffer penetration in the gel surface. The sample was layered on the beads surface and left to penetrate into the beads. The inlet tubing was filled with buffer and connected into the column. The column outlet was connected to an automatic fraction collector and one $\mathrm{ml}$ of each fraction was collected. The absorbance of each fraction was measured at $280 \mathrm{~nm}$ for protein content determination. Fractions exhibiting high absorbance at fist peak were collected together and under gone to estimation of protein content and then analyzed by SDSPAGE under reduction conditions.

Characterization of the antigen by sodium dodecyl sulfate- polyacrylamide gel electrophoresis (SDS-PAGE) (Harlow and Lane, 1988; Myers, 1995): The eluted protein fractions resulted from the different purifications methods were analyzed by $12.5 \%$ SDSPAGE. The gel and sample were prepared under reducing condition then the current was turned on and the run was started by 120 volt and continued until the samples reached the bottom of the gel (about $2 \mathrm{~h}$ ). The gel was fixed and stained in $0.1 \%$ Coomassie Blue, then excess dye was removed from the gel by destaining solution to visualize the protein bands. Protein bands were appeared at 2 locations; 18 kilodalton ( $\mathrm{kDa}$ ) and $66.6 \mathrm{kDa}$ which represent purified protein antigen (Fig.1). The parasite antigen was kept frozen at $-20^{\circ} \mathrm{C}$ until further use.

Production and purification of polyclonal Antibodies: Rabbit anti-filarial serum was obtained by immunizing the rabbit with $s i$ taria purified protein antigen. The rabbit received priming dose intramuscular injection [1 mg antigen mixed 1:1 in Freund's complete adjuvant (Sigma)]. Three booster doses were given, each was $0.5 \mathrm{mg}$ antigen emulsified in incomplete Freund's adjuvant. The first booster dose was two weeks after the priming dose. The following two booster doses were given at weekly intervals.

Test blood samples were withdrawn from rabbit before the injection of each immunizing dose. They were tested for the presence 
of specific anti-filarial antibodies by indirect ELISA. The rabbit was bled for collection of serum one week after the last booster dose. The total protein content of crude rabbit serum containing anti filarial antibody was $16.3 \mathrm{mg} / \mathrm{ml}$. It was purified by $50 \%$ ammonium sulfate precipitation method where the protein content was $10 \mathrm{mg} / \mathrm{ml}$ (Odutayo and Odunuga, 2013). More purification of IgG pAb was performed by $7 \%$ caprylic acid method, the protein content dropped to 6.4 $\mathrm{mg} / \mathrm{ml}$ (Mckinney and Parkinson, 1987). Rabbit serum which contained anti-filarial polyclonal antibodies was fractionated and kept at $-20^{\circ} \mathrm{C}$ (Fagbemi et al, 1995).

Conjugation of the antifilarial antibodies with gold nanoparticles: Gold nanoparticles were purchased from Nano tech Egypt Company (6 October City) to be conjugated with the prepared polyclonal antibodies. This depends on three types of interactions; hydrophobic interactions, ionic interactions and dative binding. Hydrophobic interactions are due to attraction between hydrophobic parts of the antibody and the metal surface, resulting in the formation of a noncovalent bond. Ionic interactions are formed between positively charged groups in antibodies, (positively charged amino acids and the N-terminal) and the negatively charged surface of the nanoparticles. Dative binding is the formation of a covalent bond between the gold nanoparticles and free sulfhydryl groups of the antibody (Hermanson, 2008).

To thirty $\mathrm{mL}$ of the prepared AuNPs, $45 \mu \mathrm{L}$ of $1 \mathrm{mM}$ mercaptoundecanoic acid (MUA) in ethanol (Sigma Aldrich, Germany) was added. The solution was mixed and left overnight at $4^{\circ} \mathrm{C}$. Two nm of AuNPs-MUA solution was prepared from stock solution by diluting with deionized water. The $\mathrm{pH}$ was adjusted to 7.4 using $0.1 \mathrm{M} \mathrm{NaOH}$ (Pronalab, Germany). Two mg of anti-filaria pAb was added to $5 \mathrm{ml}$ of AuNPs-MUA (2nm; $\mathrm{pH}=$ 7.4). In trying to obtain more robust AuNPs$\mathrm{pAb}$ conjugates, covalent linkage between pAb and AuNPs-MUA was done by using N-hydroxysuccinimide/1-Ethyl-3-[3dimeth- ylaminopropyl] carbodiimide (NHS/EDC) cross-linkers (NHS: Fluka, Germany). Five $\mathrm{mL}$ of a mixture of $5 \mathrm{mM}$ sodium phosphate buffer ( $\mathrm{pH}=7), 1.2 \mathrm{mM}$ NHS \& 2.8mM EDC were added to $5 \mathrm{ml}$ of AuNPs-pAb conjugates. Mixture was mixed and left to incubate overnight at $4^{\circ} \mathrm{C}$ that allowed the electrostatic binding between pAb \& AuNPs MUA. The conjugate was prepared in gla-ss containers to prevent aggregation to plastic vials walls (Mukherjee et al, 2005).

Detection of circulating filarial antigen by traditional sandwich ELISA: The microtitration plates were coated with $100 \mu \mathrm{l} /$ well of anti-filarial IgG pAb, incubated overnight at room temperature and washed 3 times with 0.1M PBS/T, pH 7.4. Wells were blocked with $100 \mu \mathrm{l} /$ well of $2.5 \%$ fetal calf serum per phosphate buffer saline per tween (FCS/ $\mathrm{PBS} / \mathrm{T}$ ), incubated for $2 \mathrm{hr}$ at $37^{\circ} \mathrm{C}$ and washed 3 times with PBS/T. $100 \mu 1$ of each human serum sample was pipetted into the wells in duplicate, incubated for $2 \mathrm{hr}$ at $37^{\circ} \mathrm{C}$ and washed 3 times. Then, $100 \mu 1 /$ well of peroxidase-conjugated $\mathrm{pAb}$ of $1 / 100$ for IgG was then added, plates were incubated for 1 $\mathrm{hr}$ at room temperature. Plates were washed 5 times with washing buffer. Substrate solution $100 \mu 1$ was added to each well and plates were incubated in the dark at room temperature for $30 \mathrm{~min}, 50 \mu \mathrm{l} /$ well of $8 \mathrm{~N} \mathrm{H} 2 \mathrm{SO} 4$ was added to stop the enzyme substrate solution. Absorbance was measured at $492 \mathrm{~nm}$ using ELISA reader (Nutman, 2013)

Detection of circulating filarial antigen by nano-sandwich ELISA: For diagnosis of filariasis by nano-sandwich ELISA, the same steps were adopted by using conjugated antifilarial antibodies with gold nano-particles instead of the non-conjugated ones.

Statistical methods: Data were collected and entered to the computer using SPSS proprogram, version 20; Inc., Chicago (Snedecor and Cochran, 1981). Data were entered as numerical or categorical, as appropriate.

Two types of statistics were done; descriptive included mean, $\mathrm{SD}$, range, frequency percent and analytical included Chi-square 
test, risk ratio, student t-test, ROC curve, sensitivity, specificity, positive and negative predictive values. The P-value less than 0.05 was considered statistically significant.

\section{Results}

The results were given in tables $(1,2,3,4$, $5 \& 6)$ and figures $(1,2,3,4 \& 5)$.

Table 1: Demographic data $(n=142)$

\begin{tabular}{|c|c|c|c|c|c|c|c|}
\hline \multicolumn{2}{|c|}{} & Filariasis $(\mathrm{n}=78)$ & Others $(\mathrm{n}=54)$ & Control $(\mathrm{n}=10)$ & Total & $\mathrm{P}$ value \\
\hline \multirow{2}{*}{$\begin{array}{c}\text { Resi- } \\
\text { dence }\end{array}$} & Rural & Frequency & 68 & 27 & 8 & 103 & \multirow{2}{*}{.001} \\
\cline { 2 - 7 } & & $\%$ & $88 \%$ & $50 \%$ & $80 \%$ & $72.5 \%$ \\
\cline { 2 - 7 } & $\begin{array}{c}\text { Ur- } \\
\text { ban }\end{array}$ & Frequency & 10 & 27 & 2 & 39 \\
\cline { 3 - 7 } & & $12 \%$ & $50 \%$ & $20 \%$ & $27.5 \%$ & \\
\hline
\end{tabular}

Distribution of filariasis in rural areas was equal in both areas (50\%) while in $(88 \%)$ was statistically higher than in urban ones (12\%). In parasitic group, distribution ral and $20 \%$ in urban areas.

Table 2: Classification of subjects according to clinical picture

\begin{tabular}{|c|c|c|c|c|c|}
\hline \multirow{9}{*}{$\begin{array}{l}\text { Clinical } \\
\text { picture }\end{array}$} & & & Filariasis $(\mathrm{n}=78)$ & Others $(n=54)$ & Control $(n=10)$ \\
\hline & \multirow{2}{*}{ Normal legs } & Frequency & 17 & 54 & 10 \\
\hline & & $\%$ & $21.8 \%$ & $100 \%$ & $100 \%$ \\
\hline & \multirow{2}{*}{ Elephantiasis } & Frequency & 17 & 0 & 0 \\
\hline & & $\%$ & $21.8 \%$ & $0 \%$ & $0 \%$ \\
\hline & \multirow{2}{*}{ Lymphedema } & Frequency & 36 & 0 & 0 \\
\hline & & $\%$ & $46.2 \%$ & $0 \%$ & $0 \%$ \\
\hline & \multirow{2}{*}{ Redness + long streaks } & Frequency & 8 & 0 & 0 \\
\hline & & $\%$ & $10.2 \%$ & $0 \%$ & $0 \%$ \\
\hline
\end{tabular}

In filariasis group, the most prominent clinical manifestation was lymphedema $(46.2 \%)$ followed by elephantiasis and normal legs with equal percent $(21.8 \%)$, while redness was least clinical finding (10.2\%). However, in other parasite and healthy control groups, $100 \%$ of the subjects were normal without clinical manifestations.

Table 3: Detection of microfilariae in blood film in different groups

\begin{tabular}{|l|l|c|c|c|c|}
\hline \multirow{2}{*}{ Groups } & \multicolumn{2}{|c|}{ Positive cases (microfilaraemic) } & \multicolumn{2}{c|}{ Negative cases (amicrofilaraemic) } \\
\cline { 2 - 6 } & No. & Frequency & No. & frequency \\
\hline I & Filariasis $(\mathrm{n}=78)$ & 4 & $5.1 \%$ & 74 & $94.9 \%$ \\
\hline II & Other parasites $(\mathrm{n}=54)$ & - & - & 54 & $100 \%$ \\
\hline III & Healthy control $(\mathrm{n}=10)$ & - & - & 10 & $100 \%$ \\
\hline
\end{tabular}

Microfilariae were detected in thick blood films $(5.1 \%)$ filarial cases whereas $94.9 \%$ were negative. But, in other parasites and in the healthy control no microfilariae were detected in thick blood films (100\%).

Table 4: Mean \pm SD of OD readings for circulating filarial antigen in groups by sandwich ELISA of sera.

\begin{tabular}{|l|l|c|c|c|c|}
\hline \multirow{2}{*}{ Groups } & \multicolumn{2}{|c|}{ Positive cases } & \multicolumn{2}{c|}{ Negative cases } \\
\cline { 3 - 6 } & Fo. & $(\mathrm{M} \pm \mathrm{SD})$ & No. & $(\mathrm{M} \pm \mathrm{SD})$ \\
\hline I & Filariasis $(\mathrm{n}=78)$ & 64 & $(0.68 \pm 0.114)$ & 14 & $(0.065 \pm 0.23)$ \\
\hline II & Other parasites $(\mathrm{n}=54)$ & 8 & $(0.57 \pm 0.16)$ & 46 & $(0.184 \pm 0.03)$ \\
\hline III & Healthy control(n=10) & - & --- & 10 & $(0.161 \pm 0.0539)$ \\
\hline
\end{tabular}

By ELISA, 64 were positive (0.68土.114), and 14 were negative $(0.065 \pm 0.23)$. Patients with other parasites, 8 were positive $(0.57 \pm 0.16)$ and 46 were negative $(0.184 \pm$ $0.03)$. Control was negative $(0.161 \pm 0.0539)$.

The mean OD reading of negative controls $\pm 2 \mathrm{SD}$ was estimated. Cut off value was 0.263 OD reading. Tested samples showed
OD values > cut off value were positive while those showed OD values < cut off value were negative for all patients by using traditional sandwich ELISA. Cut off value was 0.263 to detect circulating filarial antigen by sandwich ELISA in subjects' sera. But, the cut off value of nano-ELISA was 0.448 . 
Table 5: Mean \pm SD of OD readings for circulating filarial antigen in groups using nano-sandwich ELISA of sera:

\begin{tabular}{|l|l|c|c|c|c|}
\hline \multirow{2}{*}{ Groups } & \multicolumn{2}{|c|}{ Positive cases } & \multicolumn{2}{c|}{ Negative cases } \\
\cline { 2 - 6 } & No. & $(\mathrm{M} \pm \mathrm{SD})$ & No. & $(\mathrm{M} \pm \mathrm{SD})$ \\
\hline I & Filaria $(\mathrm{n}=78)$ & 72 & $(0.826 \pm 0.115)$ & 6 & $(0.006 \pm 0.007)$ \\
\hline II & Other parasites $(\mathrm{n}=54)$ & 2 & $(0.546 \pm 0.019)$ & 52 & $(0.159 \pm 0.07)$ \\
\hline III & Healthy control $(\mathrm{n}=10)$ & --- & ---- & 10 & $(0.0256 \pm 0.102)$ \\
\hline
\end{tabular}

By using nano-sandwich ELISA, 72 were positive $(0.826 \pm 0.115)$, and 6 were negative $(0.006 \pm 0.007)$ in filariasis patients. Patients with other parasites, 2 were positive $(0.546 \pm$ $0.019)$ and 52 were negative $(0.159 \pm 0.07)$.
Control was negative $(0.0256 \pm 0.102)$. By using nano-ELISA, other parasites were low compared to traditional ELISA that proved higher sensitivity and specificity than nanoELISA.

Table 6: Sensitivity, specificity, PPV and NPV of sandwich ELISA and nano-sandwich ELISA methods of serum samples for circulating filarial antigen in patients

\begin{tabular}{|c|c|c|c|c|}
\hline Techniques & Sensitivity\% & Specificity\% & PPV\% & NPV\% \\
\hline Sandwich ELISA & $90.7 \%$ & $75 \%$ & $84.8 \%$ & $84 \%$ \\
\hline Nano-Sandwich ELISA & $95.1 \%$ & $87.5 \%$ & $92.9 \%$ & $91.3 \%$ \\
\hline
\end{tabular}

In ELISA, the sensitivity, specificity, positive predictive value (PPV) and negative predictive value (NPV) were 90.7\%, 75\%, $84.8 \%$ \& $84 \%$ respectively. In nano-sand-

Table 7: Incidence of positivity for filarial detection using sandwich ELISA and nano sandwich ELISA in sera of groups.

\begin{tabular}{|l|l|l|l|l|l|}
\hline \multirow{2}{*}{ Groups } & \multicolumn{2}{|l|}{ Sandwich ELISA } & Nano sandwich ELISA \\
\cline { 2 - 6 } & Positive No. & $\%$ positivity & Positive No. & $\%$ positivity \\
\hline I & Filaria $(\mathrm{n}=78)$ & 64 & $82 \%$ & 72 & $92.3 \%$ \\
\hline II & Other parasites $(\mathrm{n}=54)$ & 8 & $14.8 \%$ & 2 & $3.7 \%$ \\
\hline III & Control $(\mathrm{n}=10)$ & - & - & - & - \\
\hline
\end{tabular}

By sandwich ELISA, 64 were positive $(82 \%)$ in filariasis patients while in patients with other parasites, 8 were positive (14.8\%). By nano-ELISA, 72 were positive (92.3\%) in filariasis patients and patients with other parasites 2 were positive (3.7\%).

\section{Discussion}

Lymphatic filariasis is a mosquito-borne infection. The adult worms live in the afferent lymphatics (and/or lymph nodes) while the microfilariae circulate in the peripheral blood where they are available to infect mosquito vectors when they feed. lymphatic filarial disease is the second leading parasitic cause of disability. Although two thirds of the 120 million infected people have subclinical infections, around 40 million have episodic adeno-lymphangitis, lymphedema, hydrocele and elephantiasis (Nutman, 2013). New diagnostic tools that have been developed for detection of infection by W. bancrofti in human population have opened up new possibilities in terms of interrupting transmission and consequently the elimina- wich ELISA showed sensitivity, specificity, PPV and NPV were 95.1\%, 87.5 \%, 92.9\% \& $91.3 \%$ respectively. tion of filariasis (Molyneux et al, 2000). Until the early 1990s, the only available parasitological method for the evaluation of individuals or populations infected with $W$. bancrofti was the thick blood smear (Eberhard and Lammie, 1991). However, due to its low sensitivity, this method does not allow accurate determination of the true prevalence of infection (McCarthy, 2000). Moustafa et al. (1998) reported that antigen detection assays may facilitate earlier diagnosis than antibody tests, as production of detectable levels of specific immunoglobulin needs time. Antigen detection assay in serum is generally performed by sandwich ELISA (Abraham et al, 2003). Nano-diagnostics can be defined as the use of man-sized materials, devices or systems for diagnostic purposes. They were available for the clinical diagnosis with increased sensitivity at lower cost (Jain, 2003).

In the present study, 78 blood samples were collected from patients of lymphatic filariasis, 54 from other parasitic infected patients and 10 from healthy control per- 
sons. Most of the studied filarial cases were from the rural areas (88\%), while urban cases were $12 \%$ of all cases. There was a statistically significant difference among examined cases in relation to their residence $(\mathrm{P}<$ 0.05). However, another study showed that the majority of people live in remote rural communities were associated with lymphatic filariasis-vector-risk environment (Ivoke et al, 2015). In contrast, Sherchand et al. (2003) showed that most of cases occurred in urban areas as well as rural areas. Crowded living conditions, housing quality, inadequate waste disposal and sanitation facilities combined with seasonal migration between endemic rural areas and non-endemic urban areas shown to contribute to the growing "urbanization" of the disease (Schweinfurth, 1983; Mak, 1986).

In the current study (among endemic patients); lymphedema was the commonest clinical manifestation (46.2\%), elephantiasis $(21.8 \%)$, normal legs $(21.8 \%)$, and redness was the least detected manifestation (10.2\%). Also, lymphedema of the legs was the commonest clinical manifestations reported (Ivoke et al, 2015). This might be due to age of cases, as lymphatic obstruction increases with time, so lymphedema develops in older patients (most of patients were old).

In contrast to Weil et al. (1999), where there was very little clinical filariasis, the study detected only one case of lymphedema among the sample population.

Thick blood film was done to all persons after an hour of taking $100 \mathrm{mg}$ DEC to detect microfilaria. $5.1 \%$ of filarial diseased persons were positive for microfilaria, while 94.9\% were amicrofilaraemic. The explanation of this result is that most of the patients were chronic obstructive cases (lymphedema and elephantiasis), so lymphatics were obstructed which prevented microfilariae appearance in the peripheral blood. In another study, a rate of $38 \%$ microfilaria positivity was detected amongst the night blood of ICT (immunochromatographic card test) and $57.4 \%$ microfilaria positivity was detected amongst the samples from the DEC provocation test when ICT was compared to night blood samples and day samples after DEC provocation (Faris et al, 1993).

The present study showed that sensitivity, specificity, positive predictive value and negative predictive value of sandwich ELISA were $90.7 \%, 75 \%, 84.8 \%$ and $84 \%$ respectively. Faris et al. (1993) detected circulating filarial antigen by ELISA with a sensitivity of $97.5 \%$. ELISA gave $94 \%$ sensitive and $70 \%$ specific for detection of microfilariae antigen. Wattal et al. (2007) found that ELISA gave $100 \%$ sensitivity and $94.12 \%$ specificity. Hoti et al. (2002) by ELISA found specificity (100\%) and sensitivity $(96.8 \%)$ of samples collected at night.

In the present study, sensitivity, specificity, positive predictive value and negative predictive value of sandwich nano-ELISA were $95.1 \%, 87.5 \%, 92.9 \%$ and $91.3 \%$ respectively. Therefore, sandwich ELISA conjugated with gold nanoparticles was found to provide higher specificity, sensitivity, positive predictive value and negative predictive value compared to traditional ELISA technique. A similar study used the conjugation of gold nanoparticles (with different sizes; $20,30 \& 40$ nanometer and different synthesis methods) to mouse anti-human IgG was evaluated for an immunochromatographic (ICG) strip test to detect brugian filariasis, it was found that conjugated $\operatorname{IgG}$ with gold nanoparticles (Au-NPs) synthesized using seeding-growth method had faster detection times, as compared with the Au-NPs synthesized using the citrate reduction method. Also, 30nm AuNPs demonstrated the best performance because it displayed the best sensitivity and the highest specificity when tested with serum samples from brugian filariasis patients and controls (Makhsin et al, 2012). Also, Moharm et al. (2014) reported that the novel nano-diagnostic assay for diagnosis of human giardiasis showed higher sensitivity, specificity, PPV and NPV (95.8\%, $95 \%, 97.2 \%$ \& 92.6\%) compared to traditional sandwich ELISA $(93 \%, 92.5 \%, 95.7 \%$ 
\& $88 \%$, respectively). Sandwich ELISA with paramagnetic nanoparticles detected echinococcosis (Koura et al, 2015) with sensitivity, specificity, PPV and NPV of $95.2 \%$, $95.5 \%, 97.6 \% \& b \quad 95.5 \%$ respectively. Those of sandwich ELISA were $90.48 \%$, $91.3 \%, 95 \%$ \& $91.3 \%$ respectively.

\section{Conclusion}

Using nano-sandwich ELISA technique for detection of circulating filarial antigen in $W$. bancrofti patients gave higher sensitivity and specificity than the traditional ELISA technique. The better diagnostic parameters of nano-gold particles were due to high binding capacity and rapid reaction kinetics of solutions. So, sandwich ELISA with paramagnetic nanoparticles gave higher specificity and sensitivity compared to a microplate-based ELISA technique.

\section{References}

Abdel-Megeed, KN, Abdel-Rahman, EH, 2004: Fasciola gigantica, immunization of rabbits with proteins isolated from coproantigen. J. Egypt. Soc. Parasitol. 34, 2:631-42.

Abraham, AM, Kannangai, R, Sridharan, G, 2003: Nanotechnology: A new frontier in virus detection in clinical practice. Ind. J. Med. Microbiol. 26, 4:297-301.

El-Bashier, ZM, Hassan, MI, Mangoud, AM, Etewa, S, Morsy, TA, 2006: A preliminary pilot survey (Culex pipiens) Sharkia Governorate, Egypt. J. Egypt. Soc. Parasitol. 36, 1:81-92.

Bradford, MM, 1976: A rapid and sensitive method for the quantitation of microgram quantities of protein utilizing the principle of protein dye binding. Anal. Biochem. 72: 248-54.

Buzea, C, Pacheco, I, Robbie, K, 2007: Nanomaterials and Nanoparticles: sources and toxicity. Biointerphases 2: 17-21.

Eberhard, ML, Lammie, PJ. 1991: Laboratory diagnosis of filariasis. Clin. Lab. Med. 11:9771010.

Fagbemi, BO, Obarisiagbon, IO, Mbuh, JV, 1995: Detection of circulating antigen in sera of Fasciola gigantica infected cattle with antibodies reactive with a Fasciola-specific $88-\mathrm{kDa}$ antigen. Vet. Parasitol. 58:235-46.

Faris, R, Ramzy, RM, Gad, AM, Weil, GJ, Buck, AA, 1993: Community diagnosis of bancroftian filariasis. Trans. R. Soc. Trop. Med. Hyg. 87, 6:659-61.
Garcia, LS, Bruckner, DA, 2001: Filarial nematode. In: Garcia, LS, Bruckner, DA, (eds) Diagnostic Medical Parasitology $4^{\text {th }}$ ed. Washington.

Gounoue-Kamkumo, R, Nana-Djeunga, HC, Bopda, J, Akame, J, Tarini, A, Kamgno, J, 2015: Loss of sensitivity of immunochromatographic test (ICT) for lymphatic filariasis diagnosis in low prevalence settings: consequence in the monitoring and evaluation procedures. BMC infect. Dis. 15:57-9.

Halawani, A, 1951: Endemic diseases control. J. Egypt. Med. Assoc. 34, 6:347-58.

Harlow, E, Lane, D, 1988: Antibodies: A laboratory manual. $1^{\text {st }}$ Ed. New York: Cold Spring Harbor Laboratory Press.

Hermanson, G, 2008: Bioconjugate techniques, $2^{\text {nd }}$ ed. San Diego: Academic Press.

Hoti, SL, Elango, A, Radjame, K, Yuvaraj, J, Pani, SP, 2002: Detection of day blood filarial antigens by $\mathrm{Og} 4 \mathrm{C} 3$ ELISA test using filter paper samples. Natl. Med. J. India. 15, 5:263-6.

Ivoke, N, Ezeabikwa, BO, Ivoke, ON, Ekeh, F N, Ezenwaji, NE, et al, 2015: Wuchereria ba$n c r o f t i$ infection in rural tropical guinea savannah communities: rapid epidemiological assessment using immunochromatographic card test and prevalence of hydrocoele. Trop. Biomed. 32:365-75.

Jain, KK, 2003: Nanodiagnostics: application of nanotechnology in molecular diagnostics. Expert. Rev. Mol. Diagn. 3, 2:153-61.

Kabatereine, NB, Malecela, M, Lado, M, Zaramba, S, Amiel, O, et al, 2010: How to (or not to) integrate vertical programmes for the control of major neglected tropical diseases in sub-Saharan Africa. PLoS Negl. Trop. Dis. 4, 6:755.

Koura, EA, Rabee, I, Ahmed, RO, Mohamed, WA, 2015: Using of paramagnetic nanoparticales with immunomagnetic bead ELISA in diagnosis of hydatidosis (Echinococcus granulosus). World J. Pharm. Sci. 5:2321-30.

Kumar, B, Karki, S, Yadava, SK, 2011: Role of fine needle aspiration cytology in diagnosis of filarial infestation. Diagn. Cytopathol. 39:8-11.

Mak, JW, 1986: Problems in filariasis control and the need for human behavior and socio-economic research. Southeast Asian J. Trop. Med. Pub. Hlth. 17:479-85.

Makhsin, SR, Razak, KA, Noordin, R, Zakaria, ND, Chun, TS, 2012: The effects of size and synthesis methods of gold nanoparticle-conjugated MaHIgG4 for use in an immunochromato- 
graphic strip test to detect brugian filariasis. Nanotechnology 23, 49:495719.

McCarthy, J, 2000: Diagnosis of lymphatic filarial infections. In: Nutman, TB, Lymphatic Filariasis, Imperial College Press, London.

Mckinney, MM, Parkinson, A, 1987: A simple, non-chromatographic procedure to purify immunoglobulins from ascites fluid. J. Immunol. Meth. 96:271-8.

Mohanty, MC, Satapathy, AK, Sahoo, PK, Ravindran, B, 2001: Human bancroftian filariasis: a role for antibodies to parasite carbohydrates. Clin. Exp. Immunol. 124, 1:54-61.

Moharm, IM, El Enain, G, El Aswad, BW, Mahgoub, A, Hendawy, M, et al, 2014: Evaluation of nano-gold beads based-ELISA for detection of Giardia lamblia antigen in stool samples of infected patients. Middle-East J. Sci. Res. 21, 12:2264-73.

Molyneux, DH, Neira, M, Liese, B, Heymann, 2000: Elimination of lymphatic filariasis as a public health problem. Trans. Roy. Soc. Trop. Med. Hyg. 94:589-59.

Moustafa, NE, Hegab, MH, Hassan, MM, 1998: Role of ELISA in early detection of Fasciola copro-antigens in experimentally infected animals. J. Egypt. Soc. Parasitol. 28, 2:379-87.

Mukherjee, P, Bhattacharya, R, Mukhopadhyay, D, 2005: Gold nanoparticles bearing functional anti-cancer drug and anti-angiogenic agent: A "2 in 1" system with potential application in cancer therapeutics. J. Biomed. Nanotech. 2: 224-8.

Myers, RL, 1995: Animal and human immunoglobulins. In: Immunology Laboratory-Manual. $2^{\text {nd }}$ ed.; Academic Press, New York, McGraw.

Nutman, TB, 2013: Insights into the pathogenesis of disease in human lymphatic filariasis. Lymphat. Res Biol. 11, 3:144-8.

Odutayo, O, Odunuga, AS, 2013: Ammonium sulfate precipitation combined with liquid chromatography is sufficient for purification of bovine serum albumin that is suitable for most routine laboratory applications. Biochem Comp. 1: 1-6.

Padmavathy, T, Astha, M, 2010: Nano bioimaging and sensing of infectious diseases. Adv. Drug Deliv. Rev. 62, 5:424-37.
Schweinfurth, U, 1983: Filarial disease in Ceylon: a geographical and historical analysis. Ecol. Dis. 2:309-19.

Shelton, DC, Samuel, AW, Gregory, ML, 2007: Nanotechnological applications in medicine. Curr. Opin. Biotech. 18:26-30.

Shenoy, RK, 2008: Clinical and pathological aspects of filarial lymphedema and its management. Korean J/ Parasitol. 46:119-25.

Sherchand, JB, Obsomer, V, Thakur, GD, Hommel, M, 2003: Mapping of lymphatic filariasis in Nepal. Filaria J. 2:7.

Shukla, R, Bansal, V, Chaudhary, M, Basu, A, Bhonde, RR, et al, 2005: Biocompatibility of gold nanoparticles and their endocytotic fate inside the cellular compartment; a microscopic overview. Langmuir. 21:10644-54.

Simonsen, PE, Mwakitalu, ME, 2013: Urban lymphatic filariasis. Parasitol. Res. 112:35-44.

Smith, AM, Dowd, AJ, McGonigle, S, Keegan, PS, Brennan, G, et al, 1993: Purification of a cathepsin L-like proteinase secreted by adult Fasciola hepatica. Mol. Biochem. Parasitol. 62, 1:1-8.

Snedecor, GW, Cochran, WG, 1981: Statistical methods $7^{\text {th }}$ edition by Technometrics.

Sun, T, Chance, RR, Graessley, WW, Lohse, DJ, 2004: A study of the separation principle in size exclusion chromatography. Macromolecules 37:4304-12.

Tomar, A, Garg, G, 2013: Short review on application of gold nanoparticles. Glob. J. Pharmacol. 7:34-8.

Waizy, H, Weizbauer, A, Modrejewsk, C, Witte, F, Windhagen, H, et al, 2012: In vitro corrosion of ZEK100 plates in Hank`s balanced salt solution. Biom. Eng. Online. 11:1-14.

Wattal, S, Dhariwal, AC, Ralhan, P, Tripathi, V, Regu, K, et al, 2007: Evaluation of Og4C3 antigen ELISA as a tool for detection of bancroftian filariasis under lymphatic filariasis elimination program. J. Comm. Dis. 39, 2:75-84.

Weil, GJ, Ramzy, RM, El Setouhy, M, Kandil, AM, Ahmed ES, et al, 1999: Longitudinal study of bancroftian filariasis in the Nile Delta of Egypt: base line data and one year follow up. Am. J. Trop. Med. Hyg. 6, 1:53-8.

\section{Explanation of figures}

Fig. 1: Characterization of antigen by SDS-PAGE gel electrophoresis: Lane 1: Molecular weight of standard protein. Lane 2: Crude filarial antigen before purification. Lane 3: Partially purified. Lane 4: Target antigen eluted from DEAE Sephadex A-50 ion exchange chromatography. Lane 5: Target antigen eluted from gel filtration chromatography on Sephacryl-S-200 column.

Fig. 2: Thick blood film showing microfilaria of W. bancrofti with unstained sheath and bluish green nuclei. Giemsa stain (x100).

Fig. 3: Cut off point of OD readings for sandwich ELISA 
Fig. 4: Cut off point of OD values for nano-Sandwich ELISA.

Fig. 5: Sensitivity, specificity, PPV \& NPV of sandwich ELISA and nano-sandwich ELISA in sera for circulating filarial antigen in patients
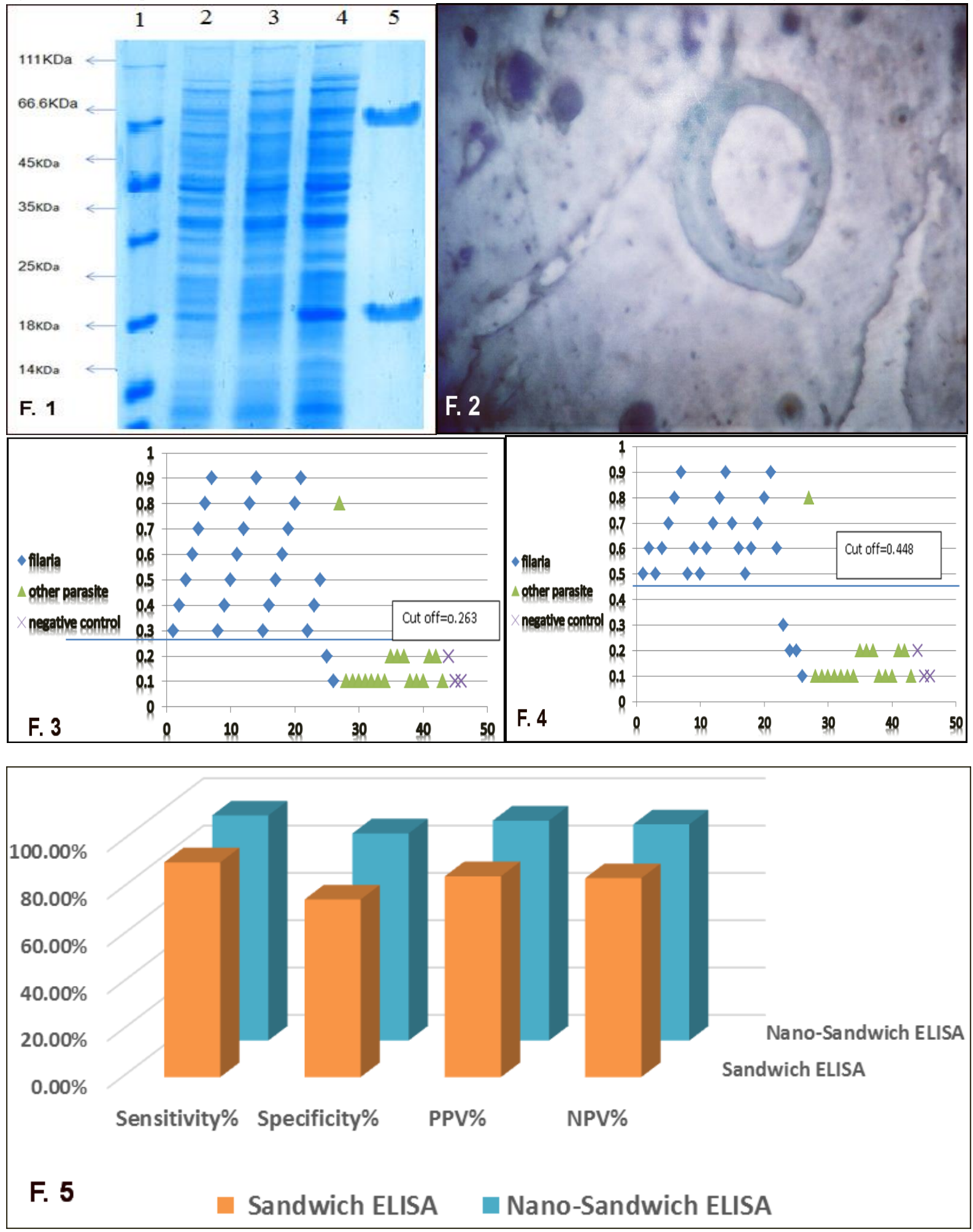